JULIA MELENTIEWA

Ośrodek Badań Czytelnictwa Rosyjskiej Akademii Nauk w Moskwie

\title{
Czytelnictwo jako narzędzie kształtowania rzeczywistości (na kanwie koncepcji noosfery Władimira Wiernadskiego $)^{1}$
}

Streszczenie. W kontekście koncepcji noosfery, wypracowanej przez wybitnego uczonego Władimira Wiernadskiego, autorka rozważa problemy czytelnictwa, szczególnie naukowego - w ujęciu globalnym. Kojarzy je z perspektywą przekształcenia rozwoju społecznego w etap wiedzy i rozumu, nazwany przez Wiernadskiego noosferą.

Słowa kluczowe: czytelnictwo, nauka, czytelnictwo naukowe, rozwój, biosfera, noosfera, Władimir Wiernadskij.

Zainteresowanie problematyką czytelnictwa ostatnimi laty najwyraźniej wzrosło. Przyczyniły się do tego wystąpienia zagranicznych oraz rosyjskich znawców - pedagogów, psychologów, a także pisarzy, dziennikarzy i innych opiniotwórców - zwracające uwagę w ogóle na czytelnictwo jako takie, a zwłaszcza na te nowe zjawiska w tym obszarze, które wiążą się ze zmianami w Galaktyce Gutenberga oraz z pojawieniem się w komunikacji środowiska wirtualnego ${ }^{2}$. Potrzebny był jednak dłuższy przedział czasu dla odpowiednio szerokiego uświadomienia, że czytanie - od tysięcy lat nierozerwalnie zintegrowane $\mathrm{z}$ pisaniem - nie tylko obecnie nie zanika, ale też podlega istotnym progresywnym zmianom.

1 Ю.П. Мелентьева, Чтение как фактор преобразования мира: $b$ контексте теории ноосферы В.И.Вернадского, Мосkbа, Изд-во „Канон-плюс”, 2017, З6стр. с илд.

2 M. McLuhan, Galaktika Gutenberga, Moskwa 2013; T. Markowa, Cztienije kak sostawnaja obraza żizni: Bumażnaja kniga ili elektronnyj tekst, „Bibliosfera” 2013, nr 4, s. 7-15; Obszczestwo i kniga: ot Gutenberga do Interneta, Moskwa 2000; G. Nikitn, W. Makarenko, Cztienije w sytuacji IT - powsiedniewnosti, Moskwa 2014; E. Schmidt, J. Cohen, The new digital age: transforming nations, business and our lives, New York, 2013. 
Oraz: że czytelnictwo wymaga wsparcia, tak ze strony władz państwowych, jak ze strony samego społeczeństwa. Bo to jest szczególnie ważna forma rozpowszechniania informacji oraz wiedzy, kształtowania umiejętności, a także: kontaktu z dorobkiem kultury³.

W Rosji czytelnictwo rozpatruje się obecnie w rozmaitych ujęciach: pedagogicznym, informacyjnym, kulturoznawczym, socjologicznym, psychologicznym, filologicznym oraz $\mathrm{w}$ jeszcze innych ${ }^{4}$. Opublikowano na ten temat niemało monografii, jak też bardziej szczegółowych artykułów oraz opracowań metodologicznych. Organizuje się również liczne konferencje przedmiotowe, fora dyskusyjne i seminaria ${ }^{5}$.

Czytelnictwo uchodzi za narzędzie kształtowania osobowości, dlatego jest traktowane jako niezbędny składnik kształcenia oraz wychowania. Ponadto przypisuje mu się silny wpływ na rozwój kompetencji werbalnych; w tym sensie jest więc czynnikiem sprzyjającym społecznym kontaktom. A poza tym stan czytelnictwa uważa się za istotny wskaźnik psychicznego zdrowia społeczeństwa, zaś w jeszcze innym ujęciu: nawet za jeden $z$ wyznaczników sprawności władz państwowych i $z$ tego powodu podlega porównaniom w skali międzynarodowej $^{6}$. Nie dziwi więc wypowiedź Prezydenta FR W. Putina zachęcająca do szerszego zainteresowania problematyką czytelnictwa ${ }^{7}$ - co miało zauważalny wpływ na rosyjską praktykę badawczą. Mimo wszystko wydaje się jednak, że istota zjawiska czytelnictwa nie została jeszcze $\mathrm{w}$ pełni rozpoznana.

${ }^{3}$ Rekomendacji po razrabotkie $i$ realizacji regionalnoj programmy poddierżki $i$ razwitija cztienija, Moskwa 2007; Nacjonalnaja programma poddierżki i razwitija cztienija (2007-2014), Moskwa 2014; Gosudarstwiennaja i obszczestwiennaja poddierżka cztienija i knigi za rubieżom. Otraslewoj analiticzeskij dokład, Moskwa 2007.

${ }^{4}$ S. Walgard, Oczerki psichołogii cztienija, Moskwa 2010; E. Grigorenko, G. Ellion, Cztienije o cztienji (fizjołogia cztienija), Woroneż 2012; U. Eco, Rol czitatiela. Issledowanije po semiotikie teksta, Moskwa 2005; Psychology of Reading, New York 2011.

${ }^{5}$ Cztienije i gramotnost' w obrazowanji i kulturze, Moskwa 2012; Cztienije kak sistema translacji duchownowop i kulturnowo opyta, Moskwa 2008; Cztienije kak strategia żyzni, Moskwa 2006.

${ }^{6}$ Cztienije w obrazowani i kulturze, Moskwa 2012; Rol cztienija w duchowno-nrawstwiennom stanowlenji licznosti, Moskwa 2011; J. Melentiewa, Cztienije w kulturie powsiedniewnosti. Obydiennoje cztienije, „Bibliosfera” 2014, nr 3, s. 7-10; N. Gejman, Why our future depends on libraries, reading and phantasy, 2013 [dokument elektroniczny].

7 W. Putin, Rossija: nacjonalnyj wopros, „Niezawisimaja gazieta” z 23.01.2012; Ukaz Prezidenta RF s 24.12.2014; Sto knig - osnowa rossijskoj kulturnoj identicznosti, Moskwa, 2012. 
Dlatego dalsze dociekania są absolutnie konieczne. I bardzo pożyteczne w tym zakresie mogą okazać się odniesienia do idei znakomitego uczonego, Władimira Wiernadskiego, a zwłaszcza do jego koncepcji noosfery $^{8}$, zaś jeszcze dokładniej - do tekstu Naucznaja mysl kak planetnoje jawlenije, opublikowanego w 1926 roku$^{9}$. Wiernadskij sformułował tam pogląd, że oto w dziejach Ziemi wygenerowała się kolejna epoka, którą nazwał noosferą (noos [grec.] - myśl, rozum) ${ }^{10}$. Jego zdaniem taka jest naturalna kolej rzeczy, że dotychczasowy, biologiczny etap rozwojowy świata, określany jako biosfera, ustępuje miejsca kolejnemu, mianowicie noosferze właśnie.

Pojawienie się noosfery - epoki zdominowanej przez rozum i wiedzę uznał Wiernadskij za proces naturalny, wpisany nie tylko w historię człowieka, lecz w ogóle w dzieje całej Ziemi jako takiej. To jest mianowicie kolejne, chociaż nadal przyrodnicze stadium rozwojowe ziemskiej egzystencji w całości.

Jednak naturalne są tylko przesłanki oraz elementarne uwarunkowania tego stanu rzeczy. Faktyczne przekształcenia rozwojowe wymagają natomiast jeszcze określonego impulsu: zamierzonych przedsięwzięć ze strony człowieka. Otóż taka aktywność od pokoleń miała i nadal ma miejsce, a jej efektem są coraz dogodniejsze warunki egzystencji społeczeństw. Głównym zaś narzędziem tej aktywnej działalności - zdaniem Wiernadskiego - była i jest wiedza naukowa. To m.in. za jej sprawą właśnie dokonuje się też transformacja biosfery w noosferę.

Bliższy rzut oka na niektóre dotychczasowe świadectwa naukowe z tego zakresu potwierdza to ponad wszelką wątpliwość.

Inne ustalenia, np. w obszarze ekonomii albo polityki, a nawet sygnały poprawiających się z biegiem lat warunków egzystencji, nie odnoszą się do tej akurat transformacji. Relacji nie widać też w roztrząsaniach filozoficznych, etycznych bądź religioznawczych. Kiedy jednak wyodrębni się do obserwacji te dotychczasowe ustalenia naukowe, które dotyczą konkretnie przemiany biosfery w noosferę, to wpływ przedsięwzięć naukowych daje się zauważyć bardzo wyraźnie ${ }^{11}$.

Rozpatrując relacje pomiędzy wiedzą naukową a rozwojem życia na Ziemi, Wiernadskij sformułował m.in. takie oto hipotezy i opinie:

${ }^{8}$ W. Wiernadskij, Biosfera i noosfera, Moskwa 1989; idem, Naucznaja mysl kak planetnoje jawlenije,. Moskwa 1991.

${ }_{9}$ W. Wiernadskij, Sobranije soczinienij, t. 3, Moskwa, 2013.

${ }^{10}$ Na podobieństwo er w geologii. W. Wiernadskij (1863-1945) był biogeochemikiem, mineralogiem i radiogeologiem. Rozwinął też i wzbogacił koncepcję noosfery, którą zaproponował austriacki geolog Eduard Suess [przyp. tłum.].

${ }^{11}$ W. Wiernadskij, Naucznaja mysl... 
- na biosferę składa się wszystko, co żyje,

- w następstwie długotrwałej aktywności naukowej ludzi biosfera przekształca się w noosferę; tak więc kreatywność naukowa wywiera wpływ na przemiany w biosferze,

- jakkolwiek w ogóle transformacja biosfery jest uwarunkowana $\mathrm{w}$ trybie naturalnym, to realizuje się w następstwie przedsięwzięć inspirowanych przez naukę,

- zatem generalnie jest ponadintencjonalna: podlega prawom przyrodniczym,

- z kolei sama nauka nie bierze się znikąd, nie jest wytworem abstrakcji, lecz generuje się z życia - pobiera materiał i przekształca w wiedzę naukową; relacje są więc dwukierunkowe.

Zdaniem Wiernadskiego, rezultaty transformacji biosfery w noosferę właśnie dlatego, że warunkowane w sposób naturalny (intencjonalne inspiracje ze strony nauki to czynnik odrębny) - wydają się trwałe. W istocie generowały się bowiem od bardzo dawna, zatem nie mogą być efemeryczne.

Biosfera, prędzej czy później, po prostu musiała przekształcić się w noosferę: w epokę wiedzy. Jednak konieczne były do tego jeszcze odpowiednie impulsy sprawcze i takie zaoferowała nauka. Pojawiały się sukcesywnie i od dawna, generowane przez rozmaite ośrodki myśli naukowej w różnych częściach świata. A w XX wieku zostały skumulowane: nastąpiła bowiem prawdziwa eksplozja dokonań naukowych ${ }^{12}$.

Wszystkie te rozważania i konkluzje Wiernadskiego opierają się na fundamentalnym założeniu wspólnym. Takim mianowicie, że kreowanym przez ludzi czynnikiem, który przyczynia się głównie do rozwoju społecznego, jest nauka. Żeby jednak istotnie miała odpowiednią moc sprawczą musi uzyskać możliwość prezentacji, utrwalenia oraz rozpowszechniania wypracowanego dorobku.

Odpowiedniego sposobu poszukiwano od dawna na całym świecie, aż w końcu dopracowano się takiej formuły. Okazała się nią - w zróżnicowanych wariantach, lecz semiotycznie tożsama - technika pisemnej rejestracji treści ${ }^{13}$. Z czasem uznana za podstawowy wyznacznik i symbol całej nowoczesnej cywilizacji ${ }^{14}$.

\section{${ }^{12}$ Ibidem.}

${ }^{13}$ W. Istrin, Wozniknowienije i razwitije pisma, Moskwa 1965; S. Awierincew: Tipołogia otnoszenija w knigie i w kulturach drewniewo Wostoka, Anticznosti i ranniewo sredniewiekowja, w: Anticznost' i anticznyje tradycji w kulturie $i$ isskustwie sowietskowo Wostoka, Moskwa 1978, s. 6-27.

${ }^{14}$ B. Semenowker, Ewolucja informacjonnoj diejatielnosti, cz. 1: Rukopisnaja informacja, Moskwa 2009; Drewnije sistemy pisma, Moskwa 1986; J. Melentiewa, Obszczaja teoria cztienija, Moskwa 2015. 
Do powstania pisma, obok tworzących się struktur oraz procedur państwowych, najbardziej przyczyniły się formy poznania i myślenia przednaukowego, mianowicie magia oraz religia. Z kolei zaś później pismo stworzyło warunki do wygenerowania nowej wersji wiedzy naukowej: właśnie pisemnej. Możliwej do utrwalenia i do zachowania w raz utrwalonej postaci.

Jednym z ważniejszych następstw była możliwość segmentacji i wyodrębnienia się naukowych specjalności. W starożytności ukonstytuowało się ich siedem - z tym, że używano wtedy sformułowania sztuki - mianowicie gramatyka, retoryka, dialektyka, geometria, arytmetyka, astronomia oraz muzyka. Później, w średniowieczu, wykorzystano ten rejestr (z uzupełnieniami) jako podstawę do powołania w Europie pierwszych uniwersytetów. W latach następnych zaś - stanowił on zespół kierunkowskazów do dalszego rozwoju nauki, już nie tylko europejskiej, lecz w ogóle światowej. Szczególnie użyteczną dla życia naukowego i niepodrabialną zaletą formuły pisemnej okazała się także odtąd możliwość transferu wiedzy pomiędzy naukowymi ośrodkami oraz uczonymi w różnych krajach.

Pismo umożliwiło więc nie tylko rejestrację produktów myśli naukowej, ale też wprowadzenie ich do rozległego obiegu. Odtąd dokonania naukowe sukcesywnie podlegały utrwalaniu oraz transmisji i stały się fundamentem całej kultury.

Kolejnym doniosłym zdarzeniem było powstanie książki drukowanej $^{15}$. To bowiem dopiero dzięki Galaktyce Gutenberga rezultaty dociekań naukowych mogły być rozpowszechniane na skalę rzeczywiście masową. Nic więc dziwnego, że wraz z pojawieniem się książek drukowanych we wszystkich krajach europejskich edytorstwo naukowe nabrało niebywałego impulsu rozwojowego. W Rosji wyglądało to tak, że od początków tamtejszego drukarstwa (1564 rok) do połowy XX wieku wydano ok. 3 mln książek (tytułów) drukowanych i znacząca ich część odnosiła się do nauki i do edukacji ${ }^{16}$. Obecnie zaś, według danych $\mathrm{UNESCO}^{17} \mathrm{Co}^{-}$ rocznie wydaje się na świecie ponad 8 mld (egzemplarzy) książek i również $\mathrm{w}$ tej liczbie edycje naukowe stanowią znaczący odsetek.

W ostatnich latach edytorstwo książek naukowych przeżywało wyraźną hossę. W wielu krajach powstały autonomiczne wydawnictwa naukowe, już to ogólne, wielodziedzinowe bądź o profilach wyspecjalizowanych. Na nieznaną wcześniej skalę rozrosły się również rejestry

${ }^{15}$ Istoria cztienija w Zapadnom mirie. Ot Anticznosti do naszich dniej, Moskwa 2008.

${ }^{16}$ E. Lichtenstein, 60 liet naucznowo knigoizdatielstwa i puti powyszenija jewo effektiwnosti, Moskwa 1977.

17 Ibidem. 
naukowych czasopism. Jednocześnie zaś nastąpiło gatunkowe zróżnicowanie publikacji naukowych: obok monografii oraz (krótszych) artykułów są również rozprawy, sprawozdania z badań, materiały postkonferencyjne i inne.

Obecnie zaś liczne publikacje naukowe pojawiają się też $\mathrm{w}$ postaci elektronicznej. Powstały nawet specjalne elektroniczne firmy wydawnicze, zajmujące się edycjami wyłącznie tekstów naukowych.

Ale to jednak forma piśmiennictwa drukowanego wygenerowała podwaliny pod trwałą rejestrację dokonań nauki. I właśnie za sprawą druku edytorstwo naukowe może pochwalić się niebywale obfitym dorobkiem, który obejmuje wszystkie istniejące zakresy nauki. No i również druk spowodował, że te zasoby są szeroko dostępne na całym świecie.

Oczywiście główną formą przejmowania treści naukowych, podobnie jak pozanaukowych, stało się w związku z tym czytanie: druga faza procesów piśmienniczego komunikowania. No bo to dopiero odbiór sprawia, że przekaz zostaje dostrzeżony albo usłyszany i następnie spożytkowany.

Procesy czytania naukowego już Francis Bacon odróżniał od innych i traktował jako szczególnie istotne warianty zachowań poznawczo-naukowych. Rzeczywiście bowiem mają odmienny charakter niż czytanie tekstów pozanaukowych. Szczególne prawidłowości tego czytania kształtowały się sukcesywnie - wraz z historycznym rozwojem samej nauki. Wydaje się, że obecnie są $\mathrm{w}$ miarę dobrze rozpoznane ${ }^{18}$.

Głównym wyróżnikiem naukowego sposobu czytania jest wysoka aktywność odbiorcza. Która bierze się stąd, że dla uczonych książki naukowe mają zazwyczaj charakter narzędzi poznawczych. Dlatego $\mathrm{w}$ trakcie czytania przeważnie ma miejsce dopełnianie treści o własne refleksje odbiorcze, uwagi oraz komentarze czytających - w następstwie zainspirowanych przez teksty ocen, przemyśleń i autodyskusji. Są to więc procesy wysoce intelektualne, myślowo pogłębione oraz precyzyjne. Można powiedzieć, że realizują się na najwyższym poziomie praktyki odbiorczej. W tym sensie, że podczas czytania naukowego zawarte $\mathrm{w}$ przekazach treści podlegają szczególnie intensywnej, aktywnej interpretacji.

Czytelnictwo naukowe ma obecnie zasięg rozległy; bez niego trudno byłoby w ogóle wyobrazić sobie funkcjonowanie nauki. Zwłaszcza że już od dłuższego czasu ma wymiar również międzynarodowy. Zatem naukowe piśmiennictwo oraz jego recepcja to jest teraz podstawowa forma

${ }^{18}$ J. Melentiewa, Obszczaja teoria...; eadem, Cztienije: modeli i modyfikacji, „Mir psichołogii" 2014, nr 4, s. 134-145. 
wzajemnego kontaktowania się uczonych, w skali zarówno krajowej, jak i globalnej ${ }^{19}$.

Natomiast nowość w tym zakresie stanowi coraz szersze wykorzystywanie elektronicznej transmisji treści naukowych. W rezultacie dostęp do nich rozszerza się jeszcze bardzieje ${ }^{20}$.

W najogólniejszym ujęciu syntetycznym: czytelnictwo naukowe przyczynia się do rozwoju rzeczywistości, a konkretnie ma również znaczący wpływ na kształtowanie się noosfery. Jest bowiem nie tylko wytworem społecznej cywilizacji, ale również narzędziem, które współkształtuje realny świat - $\mathrm{i}$ to $\mathrm{w}$ wymiarze globalnym.

Warto $\mathrm{w}$ związku z tym zwrócić uwagę na niejakie podobieństwa zjawisk, zachodzących ogólnie w światowym czytelnictwie, nie tylko naukowym - przemiany jakościowe, różnicowanie się tendencji, kryzysy do tych, które mają miejsce w całym życiu społecznym, również w skali globalnej21. Być może dlatego w celach porównawczych czytelnictwo bywa analizowane $\mathrm{w}$ wymiarze międzynarodowym, m.in. przez IFLA, i jest poddawane wspólnym, jednolitym ocenom standardowym, jak PIS, PIRLS (Progress in International Reading Literacy Study) i inne ${ }^{22}$. Częściowo bowiem z tego właśnie biorą się następnie charakterystyki poziomu życia.

To jest wystarczająco ważny powód, żeby troska o poziom czytelnictwa w ogóle, a czytelnictwa naukowego w szczególności, była nie tylko powinnością poszczególnych społeczeństw i rządów w wymiarach krajowych, ale również istotnym i wspólnym zadaniem globalnym. Taki też jest konieczny warunek, aby mogła wytworzyć się kolejna faza noosfery.

W tym celu trzeba jednak spojrzeć na procesy czytelnicze niestandardowo. Dopiero w świeżym, wolnym od sztampy ujęciu, da się wypracować nowe, produktywne przesłanki ich potraktowania. Dzięki temu zaś, być może, pojawi się szansa na wygenerowanie również wskazówek praktycznych: jak zapobiegać dalszemu regresowi stanu czytelnictwa. Ogólnego - bo czytelnictwo naukowe tej destrukcji (jeszcze?) nie podlega. To ważne, bo skala zjawiska ma przecież charakter globalny.

${ }^{19}$ J. Szczerbinina, Kniga. Tekst. Kommunikacja. Słowar - sprawocznik nowiejszich terminow i poniatij, Moskwa 2015.

${ }^{20}$ L. Bajewa, Elektronnaja kultura. Opyt fiłosofskowo analiza, „Woprosy fiłosofii” 2013, nr 6, s. 75-84; A. Woropajew, Elektronnmoje cztienije w Rossji. Opyt issledowanija, „Uniwersitetskaja kniga” 2012, nr 1, s. 36-42; M. Edem, Reading and Internet use activities of undergraduate students of the University of Calabar: Nigeria, Africa, "Journal of Library \& Information Science" 2010, nr 20, s. 11-18.

${ }^{21}$ Istoria cztienija w Zapadnom mirie...

${ }^{22}$ PISA 2012: Assessment and Analitical Framework. OECD, 2013 [dokument elektroniczny]. 
W rezultacie takiej pogłębionej refleksji być może udałoby się dodatkowo wypracować sposoby odtworzenia dawniejszego, ogólnego zasięgu książki oraz czytelnictwa. Konkretnie zaś w Rosji również: odzyskać minioną opinię społeczeństwa intensywnie czytającego.

Przeł. Jacek Wojciechowski

JULIA MELENTIEWA

Reading as a tool in developing reality (with the
case example of Vladimir Vernadsky's concept of
the noosphere)

Abstract. Within the concept of the noosphere, popularized and developed by Vladimir Viernadsky, the author considers problems of reading and reading culture, in particular that of scientific material, in a global approach. Reading culture is then identified as a complementary element in the development of human cognition that will transform the social development into a prospective stage of knowledge and reason in the earth's development, which is called by Vernadsky the noosphere.

Key words: Reading culture, science, scientific reading culture, development, biosphere, noosphere, V. Vernadsky. 